\title{
Repertoires of Collaboration for Disaster Management: Negotiating Emergent and Dynamic Systems Success
}

\author{
Deborah Bunker ${ }^{1}$, Linda Levine ${ }^{2}$, and Carol Woody ${ }^{3}$ \\ ${ }^{1}$ Discipline of Business Information Systems, University of Sydney, Sydney, Australia \\ deborah. bunker@sydney . edu . au \\ ${ }^{2}$ Independent Researcher Consultant \& University of Sydney Pittsburgh, PA, U.S.A. \\ 1lherself@gmail.com \\ ${ }^{3}$ Software Engineering Institute, Carnegie Mellon University Pittsburgh, PA, U.S.A. \\ cwoody@cert.org
}

\begin{abstract}
Disasters are emergent and dynamic scenarios involving diverse stakeholders in complex decision making and as such, disaster management systems must account for these conditions. In order to more effectively design, build and adopt these systems we suggest that emergency service agencies should consider supplementing their traditional "command and control" approaches and common operating pictures $(\mathrm{CoP})$, with purposeful "collaborative" approaches. These would facilitate the generation of a dynamic operating picture (DoP), providing a range of systems options with which to better manage disasters. Collaborative management and negotiated integration of technology and information use as well as process development, represent a paradigmatic shift in our thinking about disaster management. We have utilized McCann's (1983) Negotiated Arrangements Theory (NAT) to highlight issues and problems with traditional command and control approaches and CoP, during three disaster scenarios. As a result of lessons learned from this analysis we suggest that developing a supplementary "repertoires of collaboration" approach to the negotiation of DoP for disaster management, would have a positive impact on disaster management outcomes.
\end{abstract}

Keywords: common operating pictures, dynamic operating pictures; disaster management; information systems management; collaboration, crisis response.

\section{Introduction}

When we speak of information systems (IS) for organisational purposes, there are many models and frameworks that deal with linear and cyclic patterns of IS design, construction, adoption and use, i.e. waterfall method, prototyping, agile design. Traditionally, practitioners and academics have focused on the construction of an IS as a systems artifact which assumes that the artifact can: firstly be successfully designed to a set of pre-determined specifications; and then be created using a set of predetermined development principles that system builders can adhere to (Kroenke et al. 2012).

These assumptions are generally acceptable when organizational operations are; well-defined; highly structured; used and operated by the same people; built to 
specifications; and applied to cyclic and repetitive tasks (for example accounting, business analytics, HR etc).

Disaster management systems, however, are not characterized in this way. These systems are scenario driven and are generally ill-defined; ill-structured; selforganizing; self-reinforcing; used and operated by many different people (who often change each time the system is reconfigured); built in reaction to emerging situations; and therefore are generally applied to one-off courses of action. Disasters also move through many different phases (see Table 1) which require IS to be used in many different and flexible ways, i.e. preventing and preparing for a crisis as well as responding and recovering from it (Bunker \& Smith 2009, Ehnis \& Bunker 2012).

Traditional IS development, adoption and diffusion models, frameworks and theories, and information governance mechanisms, therefore, are not particularly effective in dealing with design, construction, adoption and use of disaster management systems. This is due to their limitations which focus on a traditional definition of complete and fixed requirements and a mechanized engineering approach to the development, adoption, diffusion and information and process compliance of such systems.

Table 1. Emergency Incident Types and Characteristics - derived in part from BlanchardBoehm (1998) Greenberg et al. (2007), Kost \& Moyer (2003), OEST (2006) and reproduced from (Bunker \& Smith 2009)

\begin{tabular}{|c|c|c|c|c|c|c|c|c|c|c|}
\hline & Medium & Agent & $\begin{array}{l}\text { Elapsed } \\
\text { Time } \\
\text { Full Effect }\end{array}$ & $\begin{array}{l}\text { Lead } \\
\text { Time } \\
\text { Warning }\end{array}$ & Amplitude & Magnitude & Area & $\begin{array}{l}\text { Contm't } \\
\text { Potential }\end{array}$ & $\begin{array}{l}\text { Local// } \\
\text { Social } \\
\text { Impact }\end{array}$ & $\begin{array}{l}\text { Plan } \\
\text { Effect }\end{array}$ \\
\hline Bomb & Various & Explosive & Short & None & High & Various & Small & Good & $\begin{array}{l}\text { Local/ } \\
\text { social }\end{array}$ & Poor \\
\hline Earthquake & Earth & $\begin{array}{l}\text { Tectonic } \\
\text { Activity }\end{array}$ & Short & Various & Various & Various & Various & Poor & Local & Medium \\
\hline Floods, & Water & $\begin{array}{l}\text { Natural } \\
\text { Activities }\end{array}$ & Long & Long & Various & Various & Various & Poor & Local & Medium \\
\hline Hazmat - land & Land & $\begin{array}{l}\text { Chemical/ } \\
\text { organic/ } \\
\text { radiation }\end{array}$ & Various & None & Various & Various & Small & Good & Local & Good \\
\hline Hazmat - sea & Water & $\begin{array}{l}\text { Chemical/ } \\
\text { organic/ } \\
\text { radiation }\end{array}$ & Various & None & Various & Various & $\begin{array}{l}\text { Small/ } \\
\text { medium }\end{array}$ & Poor & $\begin{array}{l}\text { Local/ } \\
\text { social }\end{array}$ & Medium \\
\hline Severe weather events & Air/water & $\begin{array}{l}\text { Natural } \\
\text { Activities }\end{array}$ & Various & Various & High & Various & Various & Poor & Local & Medium \\
\hline Terrorist Act & Various & Various & Various & None & High & Various & Various & Poor & $\begin{array}{l}\text { Local/ } \\
\text { Social }\end{array}$ & Medium \\
\hline Tsunami & Water & $\begin{array}{l}\text { Natural } \\
\text { Activities }\end{array}$ & Short & Short & Various & Various & Various & Poor & $\begin{array}{l}\text { Local/ } \\
\text { Social }\end{array}$ & Medium \\
\hline
\end{tabular}

What we do know is that during crises and disasters, traditional first responder command and control approaches to development of a common operating picture $(\mathrm{CoP})$ for disaster management, are utilized with varying degrees of success and effectiveness (Bunker \& Smith, 2009, Betts, 2003, Levine \& Woody, 2010). Many governments and their emergency services agencies have adopted a Prevent, Prepare, Respond and Recover (PPRR) protocol (see Figure 1) which provides a common strategy for the development of this $\mathrm{CoP}$ but most emergency agencies use their own currently proven technologies and information systems that can be enhanced and scaled to optimize outcomes and value for money to deliver the CoP. 


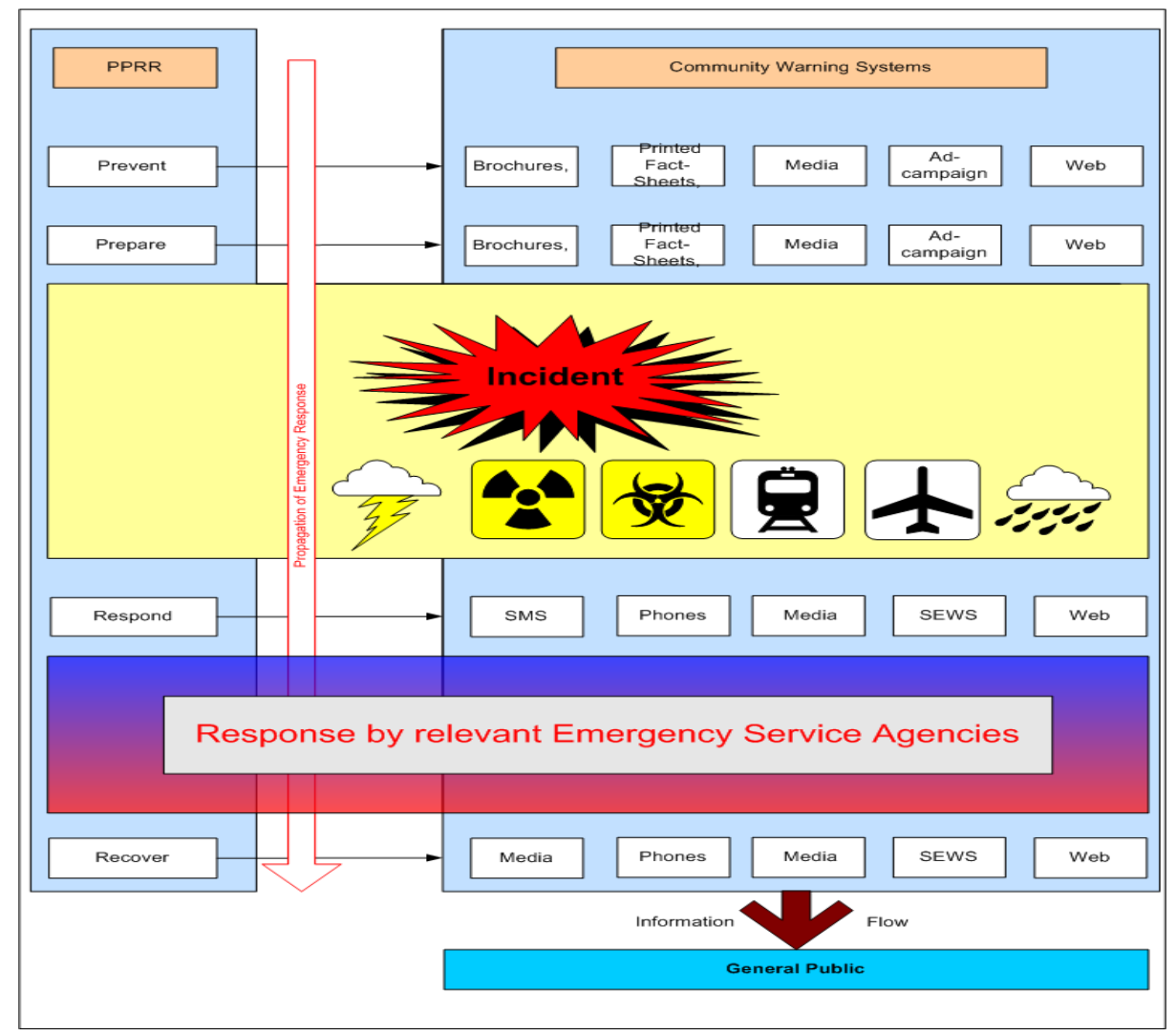

Fig. 1. Mapping of PPRR Approach to Community Warning Systems (CWS) - note changing requirements of CWS throughout an incident - diagram reproduced from (Bunker \& Smith 2009)

The term "common operating picture" $(\mathrm{COP})$ is used by emergency services agencies and the military to describe "situational awareness, by enabling multiple organisations to view and share information in a timely manner across a single picture" (DIGO website <www.defence.gov.au/digo/geoint-palanterra.htm>). We would argue, however, that in the case of disasters or crises, agencies are presented with the need for a dynamic operating picture (DoP) where there is a requirement to view multiple representations of the same phenomenon and perhaps, other representations of related phenomena by many different stakeholders with many different objectives. In order to enable a DoP, technology/information/human resources must be supplied and managed by multiple stakeholders with different objectives, and this presents a different type of complexity to $\mathrm{CoP}$ that is problematic to deal with when negotiating systems outcomes.

A common operating picture view of a disaster, therefore, does not present the full range of representations of the disaster scenario nor deal fully with the emergent and dynamic nature of a disaster. It also does not take into account the need for multiple stakeholders to be able to collaborate in order to negotiate a relevant and applicable information systems outcome for their particular disaster management requirements. 


\subsection{From CoP to DoP through Repertoires of Collaboration}

In reality, all operating picture information must be gathered, processed and delivered via a multitude of technology channels including telephone, mobile phone, SMS, facsimile, email and web pages to ensure that the disaster can eventually be effectively managed (Smith \& Bunker 2008, Bunker \& Smith 2009). This information comes from many different sources such as sensor data, satellites, geospatial systems, operational systems, business systems, emergency responders and the general public. Evaluating and authenticating this information during a disaster is problematic in its own right, but disaster scenarios are also emergent and dynamic in nature, and so they often push existing information systems and channels to failure that cannot match these requirements. This means that IS requirements for disaster management systems are also emergent and dynamic, and so need to produce systems that are resilient, flexible and fault tolerant (Pauchant et al., 1992, Pearson \& Clair, 1998). Our traditional approaches to building CoP should be re-conceptualized with emphasis on dealing with these systems characteristics which by their very nature must be derived through collaboration and negotiation between stakeholders.

This paper firstly defines collaboration using McCann's (1983) Negotiated Order Theory as a basis to develop successful DoP in disaster management. It then examines data collected by the commissions of enquiry into the Victorian Bushfires of 2009 (Parliament of Victoria 2010), 911Terrorist Attacks in 2001 (Kean 2004) and Hurricane Katrina during 2005 (Davis 2006) utilizing McCann's (1983) collaborative Negotiated Arrangements Theory as a method of analysis. IS issues and problems are then highlighted in each of these cases that impacted the ability to collaborate and negotiate a DoP. A "repertoires of collaboration" approach is then discussed with a view to the more effective provision of a DoP for any given disaster scenario, whilst reusing technology, information, human resources and "know how" in a flexible, sustainable and efficient manner.

\section{Collaboration and Negotiation for the Development of DoP for Disaster Management}

Negotiation plays an important role in organizational collaboration "so when organizations agree on an issue, negotiation is used to find the best way or the best solution to address a task. If organizations 'agree to disagree' on an issue, however, negotiation then reflects an organization's willingness to compromise in order to find common ground" (Bunker \& Smith 2009 - p 3). If an organization collaborates for a common strategy, well thought out business processes and ICT architecture can make a huge difference to this collaboration (Pang \& Bunker 2005).

Bunker and Smith (2009) interviewed a number of key managers in multiple NSW government emergency services agencies (ESA) (Police, Rural Fire Service, Ambulance, State Emergency Service, State Emergency Management Committee) and utilized McCann's (1983) Negotiated Arrangements Theory to show that disaster management DoPs: 1) have different (but aligned) ESA stakeholder objectives which also add a layer of complexity to their specification; 2) encompass different types of emergency incidents of varying complexity and so must reflect and cope with incident 
complexity; 3) must not rely solely on any one information and communications technology (ICT) platform or delivery system for their economies of scale; 4) need to integrate ESA operational, community, communication and ICT requirements to legitimize and give them a sense of direction; 5) collaborative processes require further and more detailed studies into the psychology, content and action resulting from messaging and 6) need to be developed and deployed with a view to adaptation and change.

As part of a larger disaster management project based at the University of Sydney, and commissioned by the NSW Government, Emergency Information \& Coordination Unit (EICU) a geospatial data reference architecture was produced (Qumer Gill 2012). This architecture outlines the collection, storage, processing and distribution of geospatial information to emergency services agencies that then use it to manage dynamic and emergent situations such as crowd control, crises and disasters. In the analysis of this architecture it was found that DoP are heavily reliant on:

- Technological Flexibility and Connectivity - as multiple systems produce a DoP the technological flexibility to build up information layers and differing and related perspectives is essential. As there is a requirement for different agencies and organizations to manipulate this information from different locations and in different forms, then technological connectivity through different channels e.g. online, offline and mobile is also an essential requirement;

- Information Governance Mechanisms - whatever the source, information authenticity; accuracy; reliability; and legality must be guaranteed in order to make effective decisions; and

- $\quad$ Long Term Systems Sustainability and Resource Efficiency - DoP require constantly updated information, flexible systems tools and skilled personnel to be available each time they are generated, to effectively view and interpret the picture and make appropriate decisions. As this is a resource intensive activity, and in light of government budget constraints, there is also a requirement for a better understanding of how to construct a DoP as efficiently as possible in order to ensure long term systems sustainability.

McCann (1983) maintains that negotiated arrangements (processes) are also needed by organizations in a shared problem domain to ensure a workable collaborative outcome. "The inability of stakeholders to negotiate needed roles and responsibilities and perform regulative functions will ultimately limit the viability of their problem domain" (McCann 1983- p 181).

Stakeholder collaboration and negotiating is the key, therefore, to the successful development of DoP and within this study McCann's (1983) five negotiated arrangements as they apply to DoP are as follows:

(a) Diverse Stakeholder Involvement - assure that benefits accruing to stakeholders as a result of their involvement are favorably balanced against their contributions over the long run;

(b) Dealing with Uncertainty and Complexity - manage uncertainty and complexity within the domain by developing coordination and control mechanisms for implementing policies and programs; 
(c) Development of Economies of Scale - generate economies of scale or otherwise facilitate the efficient procurement and allocation of resources among stakeholders;

(d) Development of a Sense of Shared Direction - help maintain the sense of shared direction and legitimacy of that direction by creating and building a visible identity for those involved - e.g., a legally formed association or cooperation; and

(e) Development of an Orderly Process for Adapting to Change (More Suitable ICT Architectures) - provide an orderly process for adapting to change by building the learning capacities and skills of stakeholders.

The Victorian "Black Saturday" bushfires (2009), Hurricane Katrina (2005) and 9/11 Terrorist Attacks (2001) are all typical of an emergent disaster scenario where traditional command and control CoP approaches to IS and supporting processes proved to be problematic due to lack of effective negotiated arrangements.

As negotiated arrangements are critical to dealing with dynamic and emergent incidents the following section of this paper analyzes each of these disasters in turn, using McCann's 5 negotiated arrangements as a lens of analysis to determine evidence of negotiated arrangements or the impact of their absence.

\section{Research Methods, Data Sources and Analysis}

Negotiated Arrangements Theory had been used in a prior study of a major flood debrief (Bunker \& Smith 2009) to show how various NSW Government emergency agencies collaborated to negotiate disaster management outcomes during a flood event. It was felt that this same approach would be a useful way to analyze and categorize data from a number of diverse disaster cases (bushfire, hurricane, terrorism) to understand how emergency organizations involved in these events collaborated (or not) and the resulting consequences.

\subsection{Victorian “Black Saturday” Bushfires (2009)}

\section{Scenario}

Australia is a dry and arid continent with only 5\% of the land area suitable for habitation and cultivation. Bushfires occur regularly in the southern states of Australia from October to March when temperatures rise and humidity falls giving rise to perfect fire conditions. This combined with the Australian natural vegetation of Eucalyptus trees facilitates and accelerates fire events. The Victorian fires which started in January 2009, spread rapidly on 7th February 2009. At the time there were unprecedented and "extreme" fire conditions (high temperatures, low humidity, high volumes of forest "fuel") which were identified ahead of time by the Victorian Government and the relevant fire agencies, however, many long standing fire officers had no experience of such conditions (Parliament of Victoria 2010).

Victorians were warned prior to these "extreme" conditions of the likelihood of fire outbreaks. Once the fires started the rate of their spread was uncontrollable and fire 
behavior was unique (never before experienced). As a result, of these fires 173 people died and many homes and businesses were lost at great personal and societal cost and impact.

\section{Data Sources}

Royal Commissions are major governmental enquiries into matters of public importance. They have quasi-judicial powers and the ability to compel witnesses to testify. Because of the circumstances and outcomes of these fires, including the tragic loss of so many lives, the Victorian government chose to hold a Royal Commission into these events. This commission ran from February 2009 and concluded its final report in June 2010 (Parliament of Victoria 2010) which is the primary input for the analysis in this paper.

Over 1200 public submissions were received and used to frame the investigation of the Commission. Those submissions that were ranked highest and that impacted the use of IS and supporting processes to form a common operating picture were; disaster warnings (430 submissions ranked $3^{\text {rd }}$ highest) and emergency communications (140 submissions). It is these areas of the report which are the subject of our analysis.

The report classified its investigation and recommendations into: warnings (types and processes); information (how it is used); relocation; "Stay or go" policy; risk and refuge; incident management; emergency management; commonwealth response; and emergency calls and so the interpretation of the evidence also lends weight to the importance of IS and process issues in disaster management.

\section{Data Analysis - Negotiated Order Theory}

\section{(a) Diverse Stakeholder Involvement}

Incident control centers (a shared resource) were not properly staffed and equipped to enable immediate operation in the case of these fires. State Emergency Response Plans (shared plans with input of resources from control agencies responsible for warnings) needed to be amended to focus on: "managing the message" i.e. "stay or go" policy. There was also no effective higher level emergency management and coordination arrangements during the bushfire season for example for police coordination of roadblocks with warnings "Evidence revealed a number of systemic problems with the way the roadblocks operated, among them inflexibility, poor communication and denying access to firefighters" (p. 9 - Summary).

Commonwealth resources also needed to be deployed more rapidly to assist State officers to detect, track and suppress bushfires; and provision of Emergency Management Australia briefings to states were also lacking.

(b) Dealing with Uncertainty and Complexity

There was an absence of simpler and clearer language for impending disaster warning so that communication of warnings was unclear. "It became apparent during the Commission's hearings that a number of bushfire-related terms are cumbersome, have obscure meanings or are potentially confusing to the general public" (p. 20 Summary). 
There was also a lack of an orderly process for adapting to change as there was no mechanism to build on learning capacities and skills of all stakeholders from past incidents. When the situation became more complex and uncertain there was a difficulty in:

- $\quad$ posting of information by Incident Control Centers directly to ESA information portals;

- $\quad$ agreement of procedures by the Country Fire Authority (CFA) and Department of Sustainability and Environment (DSE) to create flexibility for officers of different designations to "give warnings" in the field (system of effective delegation and interagency warnings);

- $\quad$ placement of authority with Chief Officer... to issue warnings and manage risk information, co-ordination and centralization; close coordination among multiple organizations and roles for disaster response; and

- co-ordination and distribution of decision making so that information and communications dependencies were understood and managed e.g. the different organizations CFA and DSE were responsible for issuing various warnings but no entity (or shared standard) watched over the integrity of the whole system.

"The experience of 7 February also highlighted several areas in which high-level state arrangements need reform. On Black Saturday the roles of the most senior personnel were not clear, and there was no single agency or individual in charge of the emergency.......It recommends that the roles be clarified, including through organizational change" (p. 8 - Summary).

(c) Development of Economies of Scale

The Emergency Services Telecommunications Authority and Telstra Triple Zero had little warning of high risk days (Office of the Emergency Services Commissioner responsibility) so that they could allocate resources and better prepare; and incident control centers (ICCs - a shared resource) had limited scope to prepare for and respond to the emergent disaster scenario. The report highlights that "..the state of readiness of ICCs and level 3 incident management teams that staffed them varied" (p. 8 Summary) - see point (a) previous.

\section{Development of a Sense of Shared Direction}

There appeared to be no utilization and learning from the wealth of reviews and reports to government on the topics of disaster management. "The Commission notes that the recommendations of previous enquiries have not always been implemented (p. 21 Summary)" and as a result there was no consensus approach to handling warnings (see point (b) previous) nor the development of a Memorandum of Understanding $(\mathrm{MoU})$ for commercial operators on dissemination of warnings.

(e) Development of an Orderly Process for Adapting to Change (More Suitable ICT Architectures)

Whilst government was working towards a common approach to warnings through development of Common Applications Protocol (CAP) and SEWS as PPRR 
approaches this was not in an advanced enough state to be useful in this case. As the report states “...various problems became evident with information technology at incident control centres, including because the CFA and DSE used different systems and incident management team staff sometimes had difficulty gaining access to both systems. This inhibited the use and transfer of information such as warnings, maps and situation reports" (p. 10 - Summary). There was also a shortfall in the resourcing and development of a multi ESA information warning portal and limited capacity to handle a greater information "surge" capacity for extreme events i.e. need to improve efficiency of internal information function (including additional work stations). There was also a need for Commonwealth (COAG) to promote more effective emergency call service arrangements in all States.

\subsection{Hurricane Katrina (2005)}

\section{Scenario}

Hurricane Katrina was the most destructive Atlantic hurricane of 2005 and one of the five deadliest in U.S. history._. More than 1,833 people perished during Katrina and the ensuing floods, making it the deadliest hurricane since the Okeechobee hurricane in 1928. Property damage for Katrina was estimated at \$81 billion (in 2005 USD).

Katrina formed over the Bahamas and crossed south Florida as a moderate hurricane, before strengthening to a Category 5 hurricane over the Gulf. Then Katrina made her second landfall as a Category 3 hurricane on August 29 in southeast Louisiana. Much of the devastation was due to the storm surge; and the largest number of fatalities_occurred in New Orleans, Louisiana, which flooded when the levee system catastrophically failed. Eventually $80 \%$ of the city and large parts of neighboring parishes became flooded. The floodwaters lingered for weeks. The worst property damage occurred in coastal areas and towns, which were flooded over $90 \%$ within hours, with waters reaching 6-12 miles from the beach.

The failure of the levee system in New Orleans is considered the worst civil engineering disaster in U.S. history. A lawsuit was brought against the U.S. Army Corps of Engineers (USACE) and the designers and builders of the levee system as mandated by the Flood Control Act of 1965. Responsibility for the failures and flooding was laid directly on the Army Corps in January 2008. An investigation of the responses from federal, state and local governments also resulted in the resignation of Federal Emergency Management Agency (FEMA) director and New Orleans Police Department Superintendent.

The Coast Guard, National Hurricane Center, and National Weather Service were praised for their actions. They provided exact tracking forecasts with adequate lead time. Unfortunately, repeated and urgent appeals from national, state and local officials to residents to evacuate before the storm did not warn that the levees could break and fail.

\section{Data Sources}

The primary source for our analysis of Hurricane Katrina is the comprehensive special report, A Failure of Initiative: Final Report of the Select Bipartisan Committee to Investigate the Preparation For and Response to Hurricane Katrina (Davis 2006). 
There is no shortage of examples of the failure of negotiated order and so we have selected a subset, covering topics including: Hurricane Pam exercise, levees, evacuation, and finally the National Framework, also specifically known as the National Response Plan (NRP) Catastrophe Incident Annex (CIA).

\section{Data Analysis - Negotiated Order Theory}

This analysis presents us with a number of negotiated arrangements that overlap.

(a) Diverse Stakeholder Involvement AND (c) Development of Economies of Scale

The Hurricane Pam exercise of 2004 is a prime illustration of misunderstanding and a failure in these areas. This simulation, designed and run by private Baton Rouge based contractor, Innovative Emergency Management, Ltd., was sufficiently distorted so that it was unable to achieve its real objectives. The delivery of the results from the exercise was expedited so that these could be translated into operational plans. However, according to IEM President Beriwal, "the plan was not meant to provide operational detail but rather was designed to provide general guidance, a sort of "to do list" for state and localities. Beriwal characterized the exercise as a "work in progress," describing IEM's role as "facilitator and assessors of consequences" (p. 82).

The results from Pam were clearly misused and misaligned. "Some state and parish officials said they saw Pam as a "contract" of what the various parties were going to do, and the federal government did not do the things it had committed to doing. ... Beriwal said, however, the plan derived from the Pam exercise was intended as a "bridging document" designed to serve as a guide and roadmap to be used by emergency operational officials to take the Plan and turn it into more detailed individual operational plans" (p.83). The officials' viewed Pam as a contract. IEM's stance reflects a view where the results of the exercise were intended to serve more loosely as guidance or a road map that would need to be operationalized and scaled up. These conflicting views are virtually a guarantee for difficulty and dissatisfaction on both sides.

\section{(b) Dealing with Uncertainty and Complexity}

The response to Katrina was described by government officials and citizens alike as demonstrating poor leadership and poor coordination. The Katrina evacuation conveyed confusion and a lack of clarity. For example, the different parishes used a wide variety of terms to describe the level of evacuation imposed before declaring a mandatory evacuation. Jefferson Parish - the other major component of metropolitan New Orleans-never did declare a mandatory evacuation, except for the lower parts of the parish on the Gulf Coast. In a conference call among parish officials, Jefferson Parish President Aaron Broussard said he did not have the "resources to enforce" a mandatory evacuation (p. 110).

The wide variety of terms might suggest desired precision and accompanying rules to govern different conditions, but in this instance the effect was opposite, resulting in confusion and large parts of the population remaining in their home at great peril and not evacuating. "Why would you get in the public media and ask a city, where 80 percent of its citizens ride public transit, to evacuate? What [were] they supposed to do? Fly? (p. 111). 
The situation with the levees-flood walls which broke and flooded major portions of New Orleans - can be described as a "catch 22" around requirements and dealing with uncertainty and complexity. While federal regulations require monitoring levees during periods of potential flooding, the requirement is impractical to implement during a hurricane" (p. 87). In this circumstance, at once, there are requirements with no act of responsibility assigned at the same time as there are impractical requirements. The "standard project hurricane" was used nationwide for all hurricane protection projects where the loss of human life is possible. According to the US Army Corps of Engineers, the "standard project hurricane" was used to design the New Orleans levees and is roughly equivalent to a fast moving, or "moderate" category 3 hurricane. However, there is no direct comparison of the standard project hurricane" to a specific category on the Saffir-Simpson Hurricane Scale-which did not exist when the levees were designed. ...In addition, there is no "standard" hurricane-the actual forces that levees need to withstand are a function of several factors (p. 89).

This example is interesting in a number of ways. First, a "standard" by definition assumes structure, predictability and regularity. In Katrina, the hurricane was simultaneously treated as a standard and non standard event, and this incompatibility is an invitation for ambiguity and confusion at minimum and more likely chaos.

\section{Development of a Sense of Shared Direction}

In addition to the ambiguity and confusion that we see around a "standard hurricane," the response to Katrina revealed that local solutions were incompatible. A global perspective was missing and shared direction had not been negotiated. "The different local organizations involved had the effect of diffusing responsibility and creating potential weaknesses. For example levee breaches and distress were repeatedly noted at transition sections, where different organizations [primarily New Orleans parishes] were responsible for different pieces and thus two different levee or wall systems joined together" (pp. 91-92). One can envision a scenario where each local organization's use of rules and procedures might satisfy local needs; however, in conjunction their approaches are not interoperable. In disaster response, where the coordinated effort of many agents and agencies is vital, such errors have a critical impact.

(e) Development of an Orderly Process for Adapting to Change (More Suitable ICT Architectures)

The failure of achieving of interoperability is succinctly expressed here: "The local sponsors - a patchwork quilt of levee and water and sewer boards-were responsible only for their own piece of levee. It seems no federal, state, or local entity watched over the integrity of the whole system, which might have mitigated to some degree the effects of the hurricane" (p. 97).

\subsection{9/11 Terrorist Attacks (2001)}

\section{Scenario}

9/11 was the first multiple hijacking in the United States, and the first in the world in more than thirty years. On September 11, 2001, nineteen terrorists boarded four commercial jetliners, all transcontinental flights, carrying a maximum load of 11,400 gallons of jet fuel. Their objective was to take control of the planes once they were 
airborne and turn them into flying weapons of destruction. This was a typical summer day in New York City and Washington, D.C. Before ordinary passenger jets became fiery menaces, people in the World Trade Center and Pentagon were working at computers, reading e-mail, speaking on the phone or processing paperwork. None of the civilians seemed to know what was to happen.

Four targets had been chosen, all iconic American buildings that would send a clear message of the depth of the terrorists' hatred for the United States. All four planes crashed, killing all on board-terrorists, crew members, and passengers, along with hundreds who were killed inside the structures, on the ground, and the men and women who ran into collapsing buildings in an effort to try and save others. Only one of the four planes did not find its target. Thanks to cellular phones, passengers heard of the other crashes and chose to sacrifice themselves rather than let another plane devastate a fourth target, killing even more innocent people.

\section{Data Sources}

The Complete Investigation: 9/11 Report with Commentary by The New York Times. (Kean, 2004) was used as the primary source of information about the terrorist attack on September 11, 2001. This document provided a detailed description of the steps leading up to the attack, the actions taken by responders, victims, and government bodies tied to the scenes of the attacks, and an analysis of actions taken after the attack to address problems. The commission interviewed over 1,200 people in 10 countries and reviewed over two and a half million pages of documents, including some closely guarded classified national security documents. Before it was released by the commission, the final public report was screened for any potentially classified information and edited as necessary.

There is a wealth of relevant material to use for this analysis. We have selected examples pertaining to recognizing the threat, preparation for a possible attack, and managing first responders.

\section{Data Analysis - Negotiated Order Theory}

\section{Diverse Stakeholder Involvement AND (b) Dealing with Uncertainty and Complexity}

Information sharing among stakeholder groups was identified as a critical gap in the identification and possible deterrence of terrorists in advance of the attack. Many lost opportunities for stopping the attack were identified in hindsight (p. 549). It was found that 15 of the 19 hijackers were potentially vulnerable to interception by border authorities. Analyzing their characteristic travel documents and travel patterns could have allowed authorities to intercept 4 to 15 and more effective use of information available in the US government databases could have identified up to 3 hijackers.

However, recognizing and acting on these pieces of critical information was extremely difficult to do in advance, and technology sources were not directly linked to the screening roles where interception could have occurred.

With respect to handling complexity, frequently a significant element of information was not recognized and shared because it comes bundled with thousands of other pieces of information and is lost in the volume. Also, identification of issues within 
the noise of constant day to day chatter requires someone to be listening for the message. There was a continual focus on rules of engagement without consideration of the desired results of the interactions.

Information may not be shared because those needing the information view it differently. The FBI focuses only on investigations and not on intelligence. Information not tied to a criminal investigation is not viewed as important. Hence content related to terrorist monitoring by the CIA was not readily useful to the FBI and not valued. Current rules governing information sharing require a clearly demonstrated "need to know" before sharing occurs. This approach assumes it is possible to know in advance what information is needed and why and assumes risk of exposure inappropriately outweighs the value of wider sharing.

\section{(c) Development of Economies of Scale AND (d) Development of a Sense of Shared Direction}

A heightened terrorist threat resulted in tightened security in U.S. foreign facilities such as embassies and consulates, but precipitated no domestic response to negotiating economies of scale and efficient procurement and allocation of resources. U.S. foreign facilities have clear actions to be taken in case of threats (playbooks). No sense of shared direction was developed and domestic agencies had no game plan. Moreover, none of the organizations issuing the warnings instructed domestic agencies to develop a playbook. Even when specific threat concerns related to airlines were identified and communicated to the FAA, the responses mirrored actions taken to address hijacking and did not include consideration of a new type of terrorist (p. 379).

(e) Development of an Orderly Process for Adapting to Change (More Suitable ICT Architectures)

Responders at the WTC included members of the Port Authority, the fire department (FDNY) and the police (NYPD). Each of these groups had their own chain of command, their own communication protocols, and their own procedures and practices. Consequently, the groups did not have shared and orderly meta-processes for coordinated response. FDNY took over control of the towers to address the fire and the police worked in the surrounding areas to cover traffic flow and cordon off the area. Helicopter surveillance was provided by NYPD (p. 405). In a 17-minute period NYC and Port Authority of NY and NJ had mobilized the largest rescue operation in the city's history (over 1000 first responders), evacuation of the first tower had begun, and a decision was made that the fire in the first tower could not be fought. Then the second plane hit the World Trade Center. As the crises unfolded, the inability of various responder groups to share situational awareness information began to impact operational effectiveness (p. 422).

Victims trapped in the building were calling the 911 emergency response resources asking what to do. Although the offices in the WTC had gone through practice drills, when these were carried out the occupants were left gathering on the floor and awaiting instructions. When no instructions came due to communication failures, the occupants did not know what to do (p. 420). People from upper floors of the WTC went to the roof; helicopter evacuations were used successfully in the previous bombing. The helicopters were operated by NYPD and no FDNY personnel were placed 
in them during monitoring and decision making to determine if such a rescue option was feasible this time. The 911 operators did not receive any communication from site sources and did not know the location of the fire (floors) and could not tell people if it was possible for them to descend. They told victims to remain in place (standard response protocol) leaving the individuals trapped when many could have left safely.

The established procedures worked well as far as they went: police cleared the area and blocked further entrée; fire personnel identified what could be done to address fire and organized an orderly evacuation; port authority rescued people from PATH trains and metro below WTC; and an evacuation path was developed by fire personnel from the site directing people away from falling debris (p. 427). Each of these effective responses was handled by a single responder organization under a single command.

The limitations of the communication capabilities of FDNY with police and port authority personnel resulted in limited situational awareness being shared within the buildings. The occupants in building 2 did not know when building 1 had collapsed and did not recognize the significance of this event to their survival (many ignored the notification to evacuate when it came from another command).

In contrast, the Pentagon had rehearsed joint exercises among a range of first responders and had a clear command structure for blended response - all commands had a clear view of the site and could monitor the situation and communicate with their units. This allowed them to respond jointly to the changing situation. The circumstances of the attacked zone at the Pentagon were very different from NYC. The site was isolated physically from normal pedestrian and vehicle travel routes and under the control of a military organization with a structured military chain of command. The victims were not totally reliant on general first responder support (p. 451).

\section{Discussion}

The review of issues in collaboration and negotiation of outcomes across all three disasters show that there are many inter-dependent information, warning and communications connections that are critical, for effective disaster management. When these connections fail, generally as a result of staying with traditional command and control $\mathrm{CoP}$ approaches, there appears to be no acceptable alternative, i.e. there was no ability to negotiate a substitute disaster management picture. For example, in all three disasters there was a lack of a holistic view of the incident, i.e. lack of shared protocols (communications and procedures) and lack of ability to cope with the resulting information surge, which resulted in poor shared situational awareness of what was unfolding and the most appropriate response to it.

In the case of each disaster we see:

- Incompatibility of local responses and a lack of global management of the emerging disaster;

- Imprecise and ambiguous warnings and a lack of urgency to react/evacuate being communicated;

- A lack of oversight and sense of common purpose resulting in poor information/technical/human resource management; 
- "Paralysis" of government agencies as they did not want to be seen to be complicating disaster response by over-reacting or wasting resources;

- Poor recognition of threats (in all 3 incidents) due to lack of sharing and ownership of different views of information, which was a critical gap in recognizing the threats posed by these incidents in the first place; and

- Little coordinated oversight of the "command and control" structures between emergency agencies and their inability to flexibly and effectively share changing situational awareness.

The necessity is growing for the development of approaches to collaboration for, and negotiation of, dynamic operating pictures for disaster management. As we know, DoP rely heavily on: technological flexibility and connectivity; information governance mechanisms; long term systems sustainability and resource efficiency (Qumer-Gill 2012), while disaster management stakeholders are required to negotiate roles and responsibilities to perform regulative functions, otherwise the viability of satisfactory disaster management outcomes are at stake (McCann 1983).

McCann (1983) gives us a useful starting point by which to formulate approaches for DoP development as negotiated arrangements theory attempts to address differences in socio-organisational factors by focusing on: (a) diverse stakeholder involvement; (b) dealing with uncertainty and complexity; (c) development of economies of scale; (d) development of a sense of shared direction and (e) development of an orderly process for adapting to change (more suitable ICT architectures) in order to facilitate collaboration between organizations. By combining negotiated arrangements characteristics with DoP requirements we are able to generate a collaborative focus for disaster management, what we call "repertoires of collaboration" for governments, agencies, businesses and the community when negotiating a DoP for any given disaster scenario (see Table 2). In asking these questions of all stakeholders in each instance of a disaster, a new DoP is generated to suit the emergent and dynamic characteristics of that scenario while reusing technological/informational/human resources and process knowledge that is available to hand and which suits the new circumstances. This is a departure from the current "command and control" approach to disaster management where agencies establish a command centre to assemble a common operating picture. Our approach facilitates collaboration of decentralized stakeholders and resources for the management of dynamic and emerging scenarios.

The initially developed questions could be used to make improvements to scenario dependent technology, information and process management. In time, appropriate metrics might also be developed and trialed in order to measure costs and benefits of improvements to the use of these resources.

Further incorporation of "lessons learned" from the analysis of other disaster scenarios would give the global research community a more holistic view of the types of disaster that may occur, the various environments in which governments, agencies, business and communities operate, as well as a direction to more effectively harness and manage technical/information/human resources. This is particularly important for areas of the world where resources are scare and where a response may rely on foreign aid and personnel. Disaster scenarios in these situations, are often more complex 
Table 2. Negotiated Arrangements for a Dynamic Operating Picture

\begin{tabular}{|c|c|c|c|}
\hline DoP REQUIREMENTS $\Rightarrow$ & \multirow{2}{*}{$\begin{array}{l}\text { Technological flexibility and } \\
\text { connectivity }\end{array}$} & \multirow{2}{*}{$\begin{array}{l}\text { Information governance } \\
\text { mechanisms }\end{array}$} & \multirow{2}{*}{$\begin{array}{l}\text { Long term systems } \\
\text { sustainability and resource } \\
\text { efficiency }\end{array}$} \\
\hline $\begin{array}{l}\text { Negotiated Arrangements } \\
\text { CHARACTERISTICS }\end{array}$ & & & \\
\hline $\begin{array}{l}\text { Diverse stakeholder } \\
\text { involvement }\end{array}$ & $\begin{array}{l}\text { What technology can we supply } \\
\text { to design and deliver (enable) the } \\
\text { DoP? }\end{array}$ & $\begin{array}{l}\text { How can we supply authentic, } \\
\text { accurate, reliable and legal } \\
\text { information (quality) to the DoP } \\
\text { ? }\end{array}$ & $\begin{array}{l}\text { How do we sustain a DoP } \\
\text { architectural focus over the long } \\
\text { term while minimizing } \\
\text { organizational (process) } \\
\text { requirements? }\end{array}$ \\
\hline $\begin{array}{l}\text { Dealing with uncertainty } \\
\text { and complexity }\end{array}$ & $\begin{array}{l}\text { How do we identify the most } \\
\text { successful and simplest way to } \\
\text { technically enable the DoP? }\end{array}$ & $\begin{array}{l}\text { How can we reduce information } \\
\text { complexity while increasing its } \\
\text { quality in the DoP? }\end{array}$ & $\begin{array}{l}\text { How to we sustain a DoP while } \\
\text { minimizing process complexity? }\end{array}$ \\
\hline $\begin{array}{l}\text { Development of economies } \\
\text { of scale }\end{array}$ & $\begin{array}{l}\text { How do we collaborate with } \\
\text { other stakeholders to procure, } \\
\text { allocate and manage technologies } \\
\text { for the DoP? }\end{array}$ & $\begin{array}{l}\text { How do we collaborate with } \\
\text { other stakeholders to procure, } \\
\text { allocate and manage information } \\
\text { in the DoP? }\end{array}$ & $\begin{array}{l}\text { How do we collaborate with } \\
\text { other stakeholders to ensure long } \\
\text { term systems sustainability and } \\
\text { resource efficiency of the DoP? }\end{array}$ \\
\hline $\begin{array}{l}\text { Development of a sense of } \\
\text { shared direction }\end{array}$ & $\begin{array}{l}\text { How do we organize stakeholders } \\
\text { to identify with and enable the } \\
\text { DoP architecture? }\end{array}$ & $\begin{array}{l}\text { How do we organize to ensure } \\
\text { that all stakeholders are } \\
\text { managing information in a way } \\
\text { that enables the DoP? }\end{array}$ & $\begin{array}{l}\text { How do we organize to combine } \\
\text { architectural and informational } \\
\text { components supplied by } \\
\text { stakeholders in a sustainable and } \\
\text { efficient manner (multi- } \\
\text { stakeholder processes) }\end{array}$ \\
\hline $\begin{array}{l}\text { Development of an orderly } \\
\text { process for adapting to } \\
\text { change }\end{array}$ & $\begin{array}{l}\text { How do we retain the knowledge } \\
\text { and experience of DoP design } \\
\text { and delivery for the next disaster } \\
\text { scenario? }\end{array}$ & $\begin{array}{l}\text { How do we retain the knowledge } \\
\text { and experience of DoP } \\
\text { information sourcing and supply } \\
\text { for the next disaster scenario? }\end{array}$ & $\begin{array}{l}\text { How do we retain the knowledge } \\
\text { and experience of DoP multi } \\
\text { stakeholder processes for the next } \\
\text { disaster scenario? }\end{array}$ \\
\hline
\end{tabular}

to manage due to perceived lack of control over resource management and allocation as well as cultural conflicts between domestic and foreign personnel. Inter-regional disaster management and response is also more complex for similar reasons. Disaster management systems, information and processes could be managed to reduce complexity and conflict if we develop sufficient knowledge about these scenarios and what are appropriate responses to them.

\section{Conclusion}

Disasters are emergent and dynamic scenarios involving diverse stakeholders. To improve disaster response, we suggest that emergency service agencies should consider supplementing their "command and control" approaches and common operating pictures $(\mathrm{CoP})$, to better account for these conditions.

This paper focuses on collaboration as a means to supplement current practice, and uses McCann's (1983) Negotiated Order Theory as an analytical lens and as a basis to develop successful DoP in disaster management. We then examined data collected by the commissions of enquiry into the Victorian Bushfires of 2009 (Parliament of Victoria 2010), Hurricane Katrina during 2005 (Davis 2006) and 911 Terrorist Attacks in 2001 (Kean 2004).

Our analysis demonstrates that these three quite different disasters share common command and control CoP systems failings. This suggests that development of a negotiated DoP, rather than the usual CoP "command centre" approaches to domain specific disasters such as bushfires, hurricanes or terrorist acts, may be more appropriate for disaster management in general. The analysis provided in this paper could equally be applied to other disaster scenarios, such as the Fukoshima Tsunami (2011), 
Haiti Earthquake (2010), Gulf Oil Spill (2010) or Queensland Floods (2010/11) to highlight similarities and differences between them and then derive where CoP approaches can be best supplemented with collaboration and negotiated DoP.

Our analysis of these cases also highlights the unique socio-organizational aspects of federal, state and local governments and community groups and the resulting structural, policy and cultural roadblocks to effective disaster management. Socioorganizational factors and their impact on collaborative negotiated outcomes often literally mean the difference between life and death in a disaster scenario.

Building on the creation of a disaster scenario "bank" as well as repertoires of collaboration for the negotiation of DoP, the longer term objective of this project is the development and introduction of unique, easily understood, collaborative disaster management information and process modeling methods, organizational structures and metrics to complement the "repertoires" approach to enabling DoP. These would be useful to accelerate the maturity of government inter-agency information and process improvement approaches, as well as translating successful process improvements to other agencies, by enabling collaborative communication and adaptation of information, process and organizational change. By incorporating tools and metrics to model, compare and evaluate disaster management information and process approaches, their organization and management, government, community groups and ICT providers will be able to utilize this knowledge to facilitate optimal outcomes in disaster management regardless of scenario.

\section{References}

Betts, R.: The missing links in community warning systems: findings from two Victorian community warning information systems projects. The Australian Journal of Emergency Management 18(3), 37-45 (2003)

Blanchard-Boehm, R.D.: Understanding public response to increased risk from natural hazards: Application of the hazards risk communication framework. International Journal of Mass Emergencies and Disasters 16(3), 247-248 (1998)

Bunker, D.J., Kautz, K., Nguyen, A.: The Role of Value Compatibility in IT Adoption. Journal of Information Technology 22, 69-78 (2007)

Bunker, D., Smith, S.: Disaster Management and Community Warning (CW) Systems: InterOrganisational Collaboration and ICT Innovation. In: Pacific Asia Conference on Information Systems, Hyderabad, India, July 12 (2009)

Council of Europe, Early Warning: The Key Requests to Early Warning System (Community Awareness) - submitted by Victor Poyarkov, AP/CAT, 9 rev Or.E (2005)

Davis, T.: A Failure of Initiative: Final Report of the Select Bipartisan Committee to Investigate the Preparation For and Response to Hurricane Katrina, U.S. House of Representatives, US Government Printing Office (2006)

Ehnis, C., Bunker, D.: Social Media in Disaster Response: Queensland Police Service - Public Engagement During the 2011 Floods. In: Australasian Conference on Information Systems ACIS 2012, Geelong, Australia, December 5 (2012)

Gray, B.: Conditions facilitating interorganizational collaboration. Human Relations 38(10), 911-936 (1985)

Gray, B., Wood, D.J.: Collaborative alliances: Moving from practice to theory. Journal of Applied Behavioral Science 27(1), 3-22 (1991) 
Greenberg, M.R., Lahr, M., Mantell, N.: Understanding the Economic Costs and Benefits of Catastrophes and their Aftermath: A Review and Suggestions for the U.S. Federal Government. Risk Analysis 27(1), 83-96 (2007)

Kean, T.: The Complete Investigation: 9/11 Report with Commentary by The New York Times. National Commission on Terrorist Attacks Upon the United States. St. Martin's Press, New York (2004), http: / /www.9-11commission.gov

Kost, J., Moyer, K.: Real time warnings to citizens. Gartner Advisory Group, February 13 (2003), http: / / intranet.vic.gov.au/xgov/gartner/GGV4 .nsf

Kroenke, D., Bunker, D., Wilson, D.: Experiencing MIS, 2nd edn. Pearson Australia, Sydney, Australia (2012)

Levine, L., Woody, C.: System of Systems Analysis of Catastrophic Events: A Preliminary Investigation of Unprecedented Scenarios. IEEE HST 2010, Waltham MA, USA (2010)

McCann, J.E.: Design guidelines for social problem-solving interventions. Journal of Applied Behavioral Science 19(2), 177-189 (1983)

Nathan, M.L., Mitroff, I.I.: The use of negotiated order theory as a tool for the analysis and development of an interorganizational field. Journal of Applied Behavioral Science 27(2), $163-180$ (1991)

Office of the Emergency Services Commissioner (OESC 2006) Community Information and Warning System, Department of Justice, Victorian Government (2006)

Pang, V., Bunker, D.J.: Development of a Framework to Examine the Collaborative Process in Inter-Organisational System Adoption. In: 2nd Annual Conference on IS/IT issues in Asia Pacific (ISAP) Las Vegas, pp. 13-23 (December 2005)

Parliament of Victoria, Victorian Bushfires Royal Commission Report (July 2010)

Pauchant, T.C., Mitroff, I.I., Ventolo, G.F.: The Dial Tone Does Not Come from God! How a Crisis Can Challenge Dangerous Strategic Assumptions Made About High Technologies: The Case of the Hinsdale Telecommunication Outage. The Executive 6(3), 66-79 (1992)

Pearson, C.M., Clair, J.A.: Reframing Crisis Management. The Academy of Management Review 23(1), 59-76 (1998)

Pearson, C.M., Mitroff, I.I.: From Crisis Prone to Crisis Prepared: A Framework for Crisis Management. The Academy of Management Review 7(1), 48-59 (1993)

Qumer Gill, A.: NSW Land and Property Information EICU Reference Architecture 1.0. (October 2012)

Sikich, G.W.: Hurricane Katrina: Nature's dirty bomb incident (2005), http: / /www. continuetycentral.com/featured0247.html

Smith, S., Bunker, D.: Community Warning Systems: An Information Process and ICT Architecture Approach for Emergency Incident Response. - Issues Paper prepared for the NSW Department of Commerce (2008)

Tarrant, M.: Hurricane Katrina. The Australian Journal of Emergency Management 20(4), 32 (2005) 